\title{
Mechanisms Generating Cancer Genome Complexity: Back to the Future
}

\author{
Franck Toledo
}

Genetics of Tumor Suppression, Institut Curie, PSL Research University, Sorbonne University, CNRS UMR3244 Dynamics of Genetic Information, 26 rue d'Ulm, CEDEX 05, 75248 Paris, France; franck.toledo@curie.fr; Tel.: +33-(0)1-56-24-66-71

Received: 16 October 2020; Accepted: 11 December 2020; Published: 15 December 2020

Simple Summary: In the 1990s, fluorescent in situ hybridization approaches made it possible to analyze the early stages of gene amplification in mammalian cells. These studies established breakage-fusion-bridge cycles as a major mechanism of intrachromosomal gene amplification. They also revealed that the amplified DNA perturbed nuclear architecture and led to micronucleation, which suggested a mechanism for the shortening of amplified units. The "interphase breakage model" postulated that the tremendous genomic instability occurring at early stages of gene amplification resulted from the interweaving of an amplification mechanism (breakage-fusion-bridge cycles) and of a deletion mechanism (micronucleation and stitching of DNA fragments retained in the nucleus). This model is strikingly consistent with recent data and conclusions obtained from live-cell imaging and single cell genome sequencing. The comparison of both sets of data suggests new questions to explore.

\begin{abstract}
Understanding the mechanisms underlying cancer genome evolution has been a major goal for decades. A recent study combining live cell imaging and single-cell genome sequencing suggested that interwoven chromosome breakage-fusion-bridge cycles, micronucleation events and chromothripsis episodes drive cancer genome evolution. Here, I discuss the "interphase breakage model," suggested from prior fluorescent in situ hybridization data that led to a similar conclusion. In this model, the rapid genome evolution observed at early stages of gene amplification was proposed to result from the interweaving of an amplification mechanism (breakage-fusion-bridge cycles) and of a deletion mechanism (micronucleation and stitching of DNA fragments retained in the nucleus).
\end{abstract}

Keywords: breakage-fusion-bridge cycles; micronuclei; chromothripsis; cancer genome evolution; gene amplification; telomeres; p53

\section{Introduction}

In a recent issue of Science, Umbreit et al. used live-cell imaging with single cell whole genome sequencing (Look-Seq) to analyze the cascade of genome rearrangements following the formation of a chromosome bridge in human cells [1]. Their results led to propose that this bridge leads to a first breakage-fusion-bridge (BFB) cycle-a mutational process initially proposed by Barbara McClintock [2] — but that additional BFB cycles are interwoven with episodes of micronucleation and chromothripsis-a catastrophic event resulting from "the shattering of a chromosome or chromosomal region into tens to hundreds of pieces, some of which are stitched together in a mosaic patchwork of genomic fragments" [3]. Umbreit et al. concluded that interwoven BFB cycles, micronucleation and chromothripsis episodes may underly the ongoing evolution of cancer genomes. This conclusion is strikingly consistent with the "interphase breakage model" proposed almost 30 years ago [4]. Below is 
a recollection of the fluorescent in situ hybridization (FISH) data that led to propose the interphase breakage model, and a discussion of this model in the light of more recent studies.

\section{Early Stages of Gene Amplification are Characterized by Extreme Genomic Instability}

Genome rearrangements are frequently observed in tumor cells, encompassing net gains or losses of whole chromosomes (aneuploidy) or parts of chromosomes (deletions, non-reciprocal translocations, gene amplification) that may include complex events such as chromothripsis. Gene amplification, defined as a copy number increase of a restricted region of a chromosome, may contribute to tumor progression by increasing the copy number, and thereby the expression, of oncogenes [5]. The amplified DNA can be organized as intrachromosomal extra-copies that may form a cytologically observable homogeneously staining region (HSR), or as extra-chromosomal copies called double minutes (DMs) (Figure 1).
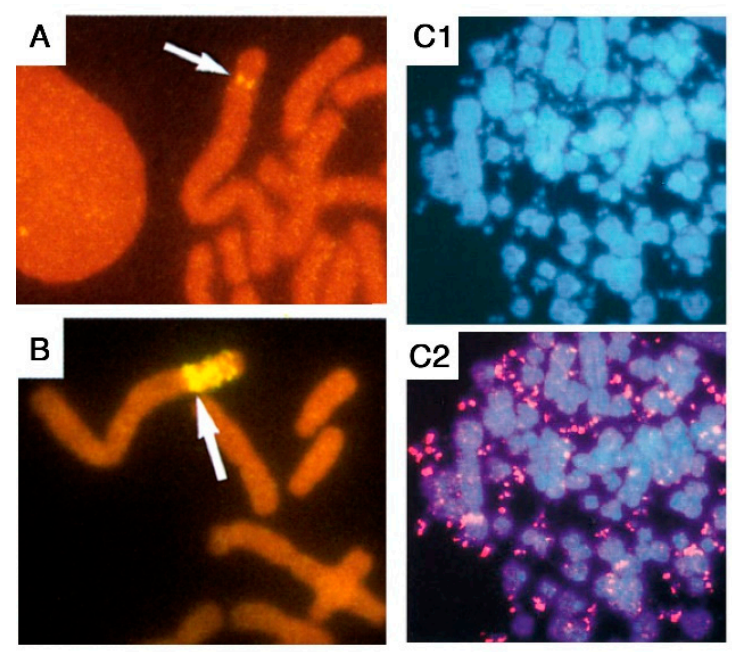

Figure 1. Gene amplification in mammalian cells can be intra- or extra-chromosomal. Fluorescent in situ hybridization (FISH) with a probe specific to the AMPD2 gene was performed in cells either unamplified (A) or exhibiting intra- (B) or extra-chromosomal (C) AMPD2 gene amplification. Partial metaphases are shown. In (A,B), a biotinylated probe was hybridized to chromosomes stained in red with propidium iodide, and the AMPD2 genes (arrows) were detected with avidin and anti-avidin antibodies coupled with FITC (yellow fluorescence). In (C), a digoxigenin-labelled probe was hybridized to chromosomes and DMs stained in blue with DAPI (C1), and the AMPD2 genes were detected (C2) with antibodies against digoxigenin coupled with TRITC (red fluorescence). Adapted from refs. [6,7].

Efforts to understand the mechanisms underlying oncogene amplification were initially hampered by the high level of genome complexity in cells recovered from advanced tumors. However, in the 1990s, several groups gained insights into these mechanisms by using model systems of cultured cells selected for resistance to a cytotoxic drug. Essential for these advances were the development of the FISH technique that made it possible to analyze the amplified DNA at the level of a single cell, and the design of experimental protocols allowing the recovery of mutant cells 10-35 generations after initiation of the amplification process. The early mutants analyzed were cells amplified for the DHFR gene, which confers resistance to methotrexate [8-11]; the CAD gene, which confers resistance to phosphonacetyl-aspartate [12-14]; the AMPD2 gene, which confers resistance to coformycin $[4,6,7,11,15]$ and the MDR1 gene, which confers resistance to drugs including vinblastin, adriamycin and actinomycin D $[7,11]$. FISH with a probe for the amplification "driver" gene (conferring drug resistance) first revealed that early amplified units, within HSRs or DMs, were often tens of Megabases $(\mathrm{Mb})$ in length, suggesting that their amplification resulted from an uneven segregation of driver sequences during successive cell cycles, rather than local over-replication $[6,8,9,12]$. Furthermore, these studies revealed a transient, but extreme genomic instability at early stages of the amplification process. 
For example, when clones were analyzed 20 cell divisions after initiation of AMPD2 gene amplification, the distribution of intrachromosomal AMPD2 extra-copies varied from cell to cell within a single clone, and one third of the cells exhibited karyotypic abnormalities such as dicentric and ring chromosomes. By contrast, clones analyzed 10 cell divisions later were more homogeneous and exhibited fewer karyotypic anomalies. The comparison of these two sets of clones suggested that chromosomes with 2-4 AMPD2 copies separated by ca. $45 \mathrm{Mb}$ corresponded to the earliest amplified structures, which were progressively overtaken by structures with more units of reduced and irregular sizes [6]. However, the precise mechanisms underlying gene amplification or the rapid shortening of amplified units remained unknown.

\section{A Major Role for Breakage-Fusion-Bridge Cycles in Gene Amplification in Mammalian Cells}

A better understanding of the mechanisms involved came from two-color FISH analyses, with one probe for $A M P D 2$, the amplification "driver" gene, and one probe for a passively co-amplified ("passenger") marker [4]. These experiments showed that the early intrachromosomal amplified units were organized as Mb-long inverted repeats with one or several orders of symmetry, which were perfectly explained by the operation of breakage-fusion-bridge cycles between sister chromatids (Figure 2). According to this model, which B. McClintock initially described as the chromatid type of BFB cycles, the sister-chromatids produced after replication of a broken chromatid would fuse at the location of the break, hence generating a dicentric chromatid. At anaphase, the centromeres of the dicentric chromatid would move to opposite poles of the mitotic spindle, creating a bridge which is later broken, and this may initiate another cycle of fusion, bridge and breakage, until some process, unknown at that time, heals the broken chromatid [2]. B. McClintock obtained evidence of this mechanism in maize cells, by observing its "bridge" and "breakage" intermediates [16], and later reported the "fusion" intermediate [17]. Likewise, at early stages of mammalian AMPD2 gene amplification, the palindromes with multiple levels of symmetry were expected products of chromatid BFB cycles [4] and the "bridge" and "fusion" intermediates, identified later [15], provided further evidence for this mechanism. The expected products and/or intermediates of chromatid BFB cycles were also observed in cells amplified for the DHFR or MDR1 genes [10,11]. Furthermore, evidence for a related mechanism, the chromosome type of BFB cycles involving dicentric and ring chromosomes [2], was found in cells amplified for the $C A D$ [13] or AMPD2 [15] genes. In AMPD2-amplified cells, chromosome BFB cycles were shown to result from secondary mutational events occurring in cells already undergoing chromatid BFB cycles [15]. Consistent with this, in another model system, BFB cycles affecting one chromosome were found to subsequently cause the instability of multiple chromosomes through translocations [18]. Together, these studies revealed BFB cycles as a major mechanism of mammalian gene amplification and chromosomal instability.

These results implied that a single double-strand break could initiate the gene amplification process $[4,10,15]$. Alternatively, dysfunctional telomeres might also initiate intrachromosomal amplification $[13,19]$. In support of the hypothesis that DNA breaks may initiate gene amplification, $B$. McClintock initially observed BFB cycles resulting from double-strand breaks caused by transposition events or by $\gamma$-irradiation [20]. Furthermore, the drugs methotrexate, phosphonacetyl-aspartate or coformycin, used to select cells amplified for the DHFR, CAD or AMPD2 genes, are known DNA damaging agents. Interestingly, despite the extreme genomic instability at early stages of AMPD2 gene amplification, amplified units of similar sizes were observed in independent $A M P D 2$-amplified clones [6], which indicated that the earliest cyclic breaks might occur at specific "fragile" sites, rather than at random locations [21], a possibility also suggested by the structure of $C A D$-amplified chromosomes [14]. In that regard, the ability to use several drugs to select for MDR1 gene amplification provided crucial information [11]. Clones with MDR1 gene amplification were selected for with adriamycin or actinomycin $\mathrm{D}$, which are both DNA damaging drugs, or with vinblastine, which only acts as a spindle poison at lower doses. Surprisingly, MDR1-amplified clones were recovered infrequently upon selection with adriamycin or vinblastin and exhibited either intrachromosomal 
or extrachromosomal amplified copies, whereas clones with MDR1 gene amplification were much more frequent upon selection with actinomycin D and always resulted from chromatid BFB cycles [11]. The difference between the two DNA damaging drugs could be explained by the fact that adriamycin induced breaks at random locations, whereas actinomycin D caused breaks at specific chromosomal loci defined as "common fragile sites," which are regions where gaps and breaks are detected at high frequency in metaphase chromosomes when cells are grown under conditions causing DNA replication stress [11]. Further analyses showed that methotrexate and coformycin were also inducing breaks at common fragile sites, and suggested that the ability of a drug to induce the amplification of a given gene relied on its ability to activate a fragile site telomeric to the gene. Furthermore, fragile sites flanking AMPD2 were found to determine the content of the earliest amplified units, accounting for units of similar sizes in independent cellular clones [11].

A

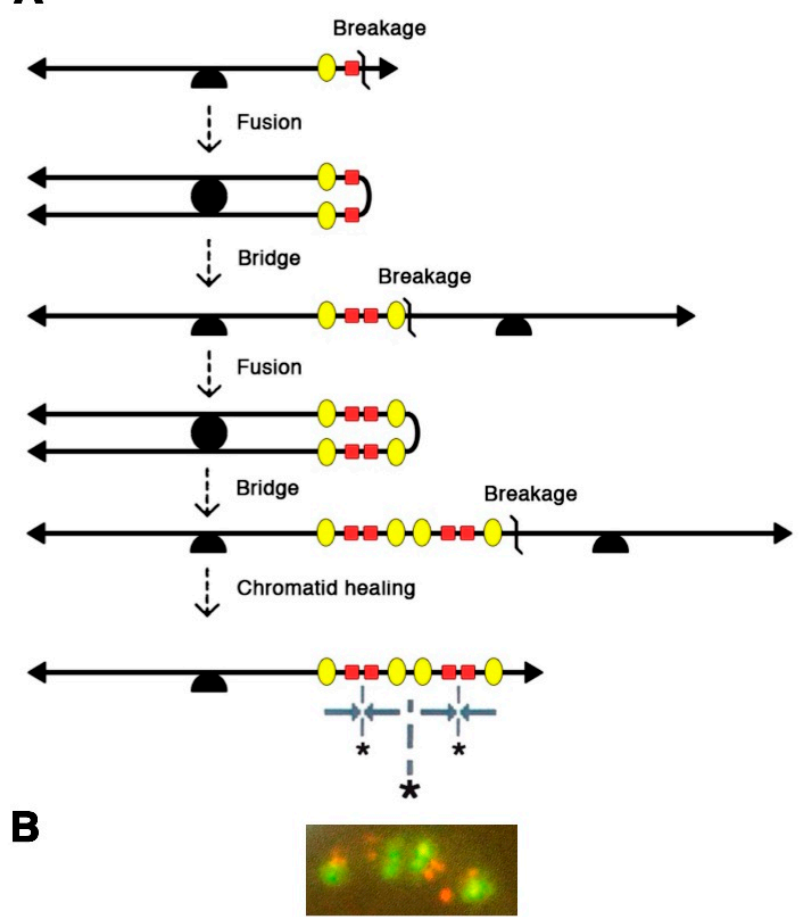

Figure 2. Chromatid Breakage-Fusion-Bridge cycles account for the symmetrical structures observed at early stages of gene amplification in mammalian cells. (A) At the earliest stages of gene amplification, breakage-fusion-bridge (BFB) cycles of sister chromatids lead to megabase-long palindromes with one or two orders of symmetry, containing equal copy numbers of the amplification driver gene (conferring drug resistance; red squares) and of the passenger marker (yellow ovals, centromeric to the driver in an unamplified chromosome). Grey arrows: orientation of amplified units; asterisks: symmetry axes; arrowheads: telomeres; half-circle: centromere. (B) Example of a palindromic structure observed on an $A M P D 2$-amplified metaphase chromosome. This structure was revealed by two-color FISH with a digoxigenin-labelled probe for the amplification driver AMPD2 (in red) and a biotinylated probe for P3C4, a passively co-amplified marker (in yellow). Adapted from Figures 2 and 4 of Ref. [4].

These conclusions relied on analyzing model systems of gene amplification, but they rapidly appeared relevant to understand the instability of cancer genomes. In the late 1980s, Hartwell and Weinert discovered the existence of cell cycle checkpoints in yeasts, and proposed that similar checkpoints might be important in mammals, particularly to ensure proper embryonic development [22]. A few years later, the observation that gene amplification in mammalian cells relies on cyclic DNA breaks [4], and that p53 controls the G1-S checkpoint [23] and prevents gene amplification [24,25], led Hartwell to propose that "defects in a cell cycle checkpoint may be responsible for the 
genomic instability of cancer cells" [26]. Furthermore, megabase-long inverted repeats were soon found in tumor cells amplified for various oncogenes (e.g., CCND2, RIN1, MET, PIP, CCND1 or $E R B B 2$ [27-32]), while bridge intermediates were reported in tumors amplified for MDM2 or the 11 13 chromosomal region [33,34], and chromatid fusions were observed in tumor cells amplified for MYC [35]. Moreover, telomere attrition caused BFB cycles and cancers in p53 mutant mice deficient for telomerase [36], and mice deficient for both p53 and a nonhomologous end joining DNA repair protein developed lymphomas with BFB cycles leading to MYC gene amplification [37]. Furthermore, evidence that the boundaries of amplified units in cancer cells might rely on breaks occurring at common fragile sites came first from analyzing reports in the Genome Data Base [11], then from experimental data [28-31,38-41]. Finally, hypoxia, a frequent property of the solid tumor microenvironment, was found to cause breaks at chromosome fragile sites and to promote the rearrangement of the amplified DNA [7].

Interestingly, in both the AMPD2 and MDR1 model systems, extrachromosomal amplification of the selected gene on DMs was observed in a few drug-resistant clones, and best explained by the looping-out of a circular molecule containing the selected gene, followed by an unequal segregation of circular molecules at subsequent mitoses [11,15]. The initiation of this amplification process is independent from BFB cycles, but a later reintegration of DMs into chromosomes may trigger secondary BFB cycles [7]. In sum, although the genome instability of cancer cells often mask the initial mechanisms responsible for oncogene amplification, evidence of BFB cycles could still be observed in some tumors, either because some early structures are selected for during the clonal expansion of tumors cells [30], or because BFB cycles might be a late rather than an initial mechanism of gene amplification in some cases [7]. In recent years, the analysis of cancer genomes shifted from cytogenetics to high-throughput genome sequencing, and algorithmic approaches to detect BFB cycles in tumor genomes were implemented [42-44]. With these approaches, BFB cycles appeared to be enriched in esophageal, lung and head and neck squamous cell cancers, and to be mostly implicated in the amplification of the CCND1, ERBB2 and CCNE1 oncogenes [45]. Importantly, prior FISH studies had reported amplification of these three genes in cancer cells, and provided evidence that BFB cycles with breaks at fragile sites or complex fragile regions might underly the amplification of CCND1 [11,28,31] and ERBB2 [32,46].

\section{Further Rearrangements of the Amplified DNA: The Interphase Breakage Model}

BFB cycles explained the intrachromosomal amplification of the AMPD2 gene, in particular the presence of inverted repeats, several tens of $\mathrm{Mb}$ in length, with several orders of symmetry. However, the observation of much shorter units very early in the amplification process suggested the possible implication of another mechanism [4]. Evidence for such a mechanism came from four distinct observations: (1) driver and passenger amplified copies alternated in Mb-long inverted repeats on metaphase chromosomes, but unexpectedly, the amplified copies of each marker often segregated into distinct nuclear domains in interphase nuclei (Figure 3A); (2) unlike cells from the parental cell line, $35 \%$ of the amplified cells exhibited nuclear malformations, ranging from nuclei with small bulges, to nuclei with large blebs or releasing micronuclei; (3) $80 \%$ of the nuclear malformations contained amplified DNA, and in most cases extra-copies of only one marker; (4) the chromosomes with larger amplified units exhibited equal numbers of driver and passenger sequences, but chromosomes with shorter units often had many copies of the driver flanked by only two copies of the passenger. Together, these observations indicated that the amplified DNA perturbed nuclear architecture, and further suggested that multiple DNA breaks occurring in a single interphase could lead to the extrusion of amplified passenger sequences in a micronucleus, and that driver-containing DNA fragments retained in the nucleus could then be stitched together to generate an amplified chromatid with shorter amplified units (Figure 3B). This chromatid might have a broken end and undergo further BFB cycle(s), leading to a chromatid with many copies of the driver flanked by two copies of the passenger (Figure 3C). 
A

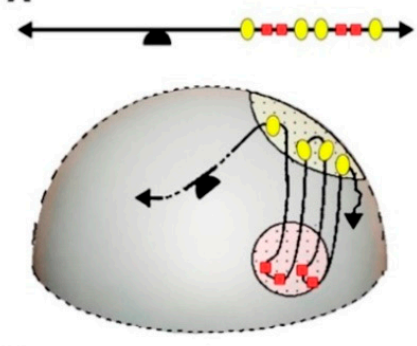

B
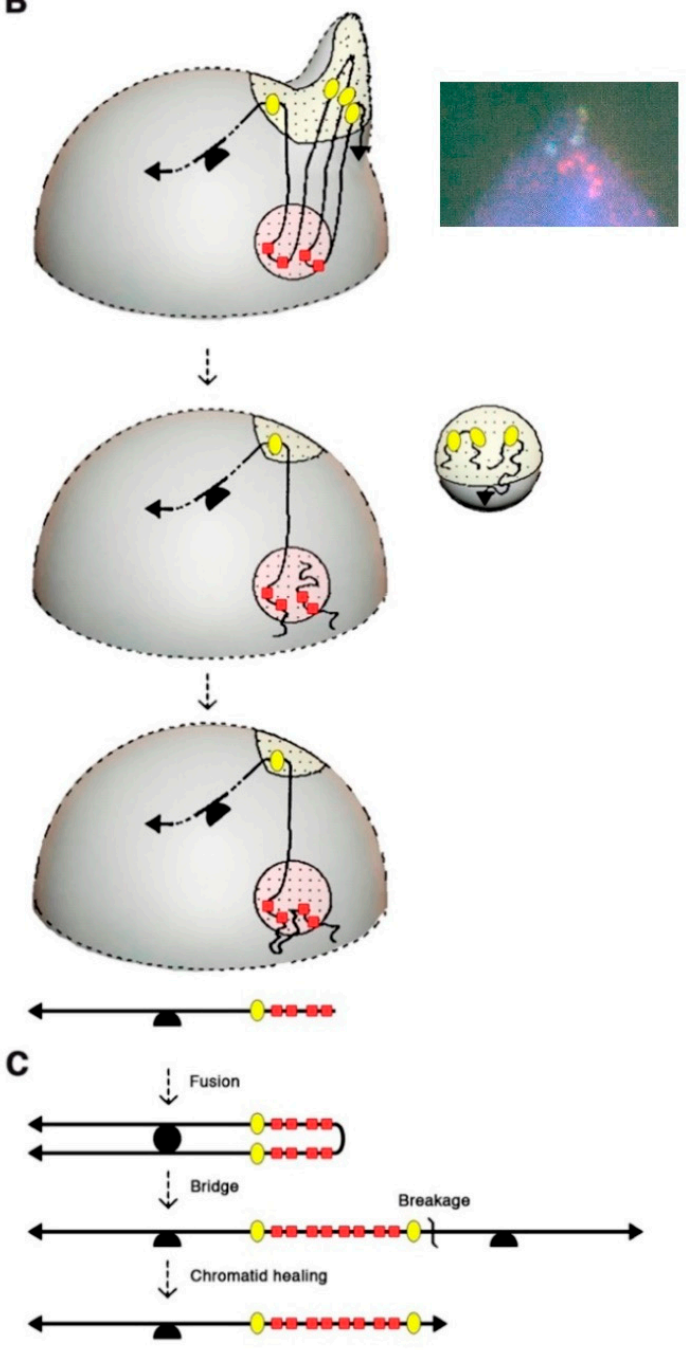

Figure 3. The interphase breakage model, integrating micronucleation, multiple DNA breaks and BFB cycles, can explain the rapid evolution of amplified chromosomes. (A) Co-amplified markers alternating in metaphase chromosomes (top) may segregate in interphase nuclei (bottom) into distinct nuclear domains (dotted areas). Red squares: amplification driver gene; yellow ovals: passenger marker; arrowheads: telomeres; half-circle: centromere. (B) The co-amplification of sequences belonging to distinct nuclear domains may perturb nuclear architecture, and lead to the extrusion of passenger sequences in a micronucleus. Micronucleus extrusion is associated with multiple DNA breaks, and the DNA fragments retained in the nucleus are stitched together to generate an amplified chromatid with an excess of driver sequences. (C) The amplified chromatid lacks a telomere and may undergo further BFB cycle(s). In (B) a typical nuclear malformation from an AMPD2-amplified cell analyzed by FISH is shown. Extra-copies of AMPD2 (in red) and P3C4 (in yellow) segregate into distinct domains, and the nuclear bulge only contains P3C4 copies. Adapted from Figures 3 and 5 of Ref. [4]. 
According to this "interphase breakage model," the tremendous genomic instability occurring at early stages of mammalian gene amplification would result from the interweaving of an amplification mechanism (BFB cycles) and of a deletion mechanism (micronucleation and stitching of DNA fragments retained in the nucleus) [4]. Furthermore, the interphase breakage model was also proposed to contribute to the frequent observation of dicentric chromosomes at early stages of gene amplification, in diploid cells if sequences from two distinct chromosomes were simultaneously extruded in a micronucleus or in polyploid cells assuming that the micronucleation process favors endo-mitotic reduplication by affecting the integrity of the nuclear membrane [15].

Again, the interphase breakage model relied on the analysis of cells resistant to a cytotoxic drug, but evidence of its potential relevance to cancer cells was soon reported. Cells from well-differentiated liposarcomas, which often exhibit abnormal chromosomes (ring or giant rod chromosomes) with amplification of the 12q13-14 region, displayed blebs and micronuclei carrying DNA from the abnormal chromosomes [47,48]. Furthermore, evidence of a relationship between bridge-breakage of a chromosome and interphase bleb or micronuclei carrying sequences of the same chromosome was reported in malignant fibrous histiocytoma cells [49]. Interestingly, in neuroblastoma cells carrying $M Y C N$ extrachromosomal amplified copies, nuclear blebs and micronuclei containing $M Y C N$ copies were reported [50], raising the possibility that the interphase breakage model might not be restricted to cells with HSRs, but could also apply to cells with DMs.

The interphase breakage model, which postulates micronucleation-induced multiple DNA breaks followed by the stitching together of DNA fragments that remain in the nucleus, can be considered as a foreshadow to chromothripsis, identified 20 years later through whole genome sequencing [3]. Interestingly, the sequestration of an anaphase lagging chromosome into a micronucleus was found to cause chromothripsis of the isolated chromosome [51,52]. However, the latter mechanism would best explain the shattering of an entire chromosome, rather than chromothripsis events limited to a chromosomal region (e.g., an HSR). Furthermore, the interphase breakage model postulated a link between BFB cycles and multiple simultaneous DNA breaks in interphase, and accordingly, several cancer genomic analyses later suggested a link between BFB cycles and chromothripsis [53-55]. Also consistent with this, dicentric chromosomes formed during telomere crisis correlated with chromothripsis events in post-telomere crisis cells [56]. In their recent study, Umbreit et al. found chromosome bridges to induce micronucleation, not immediately after breakage of the chromosome bridge, but rather in the second cell generation, and this correlated with a massive increase in chromothripsis events [1]. This appears again consistent with FISH data, because in the AMPD2 system, amplified chromosomes with 2-4 copies of the AMPD2 (driver) gene exhibited the same copy number of passenger sequences, and thus, could be explained by one or two BFB cycles (Figure 1), whereas chromosomes with 5-15 AMPD2 copies exhibited fewer copies of the passenger marker (Figure 2), suggesting that micronucleation and multiple interphase breaks occurred subsequently to the first or second BFB.

\section{Conclusions and Future Perspectives}

FISH studies and the more recent Look-Seq analyses have provided remarkably consistent data, leading to conclude that BFB cycles, micronucleation and multiple interphase DNA breaks are interwoven to drive the evolution of cancer genomes. However, while both sets of studies suggested that an amplified chromosome may give rise to a micronucleus, the proposed mechanisms for micronucleation appear to differ: in the interphase breakage model, micronucleation would result from a nuclear blebbing of the amplified DNA, whereas Umbreit et al. proposed that a micronucleus might be formed around a lagging broken chromosome. Further analyses will thus be required to precisely define the mechanisms underlying micronucleus formation. In addition, each approach generated unique information. For example, it was first assumed that spindle forces at mitosis caused the breakage of chromosome bridges in mammalian cells [57]—as initially reported in maize cells [2]—but live cell imaging revealed that chromosome bridges may persist for several hours in interphase $[1,56]$ 
and suggest a critical role for cytoplasmic actomyosin contractile forces in chromosome bridge breakage [1]. Furthermore, Look-Seq approaches revealed that chromosome bridges and micronuclei may undergo unexpected bursts of DNA replication that might contribute to chromothripsis [1], and whole genome sequencing provided evidence for a prominent role of the cytoplasmic exonuclease TREX1 in chromothriptic DNA fragmentation [58]. On the other hand, FISH studies revealed the segregation of co-amplified markers into distinct nuclear domains, an observation that could not be made with Look-Seq approaches and that was crucial to suggest the interphase breakage model. These co-amplified markers might segregate in interphase because they belong to distinct topologically associated domains [59], or to distinct nuclear subcompartments [60], which could also explain why their co-amplification can perturb nuclear architecture. This suggests that a better understanding of nuclear organization might provide additional clues about the mechanisms underlying complex cancer genome rearrangements. In this regard, the distribution of chromothripsis events [55] and chromatin domains [61] was recently reported for the same 2658 tumors, and integrating both analyses might be useful. Finally, the computational classification of complex structural variants in cancer genomes is still evolving. Complex structural variant patterns were proposed to result from BFB cycles [43], chromothripsis [3,62], chromoplexy [63] and templated insertion chains [64,65], but considering that BFB cycles and chromothripsis events may be interwoven should add further complexity. Interestingly, the Pan-Cancer Analysis of Whole Genomes Consortium recently classified chromothripsis events from 587 tumors into five categories, and two of them ("liposarcoma-like chromothripsis" and "amplified chromothripsis") show substantial overlap with BFB cycles according to a computational analysis by Hadi et al. $[45,66]$. Moreover, three new complex structural variant patterns were recently reported from analyzing junction copy number (JCN) in cancer genomes: pyrgo, rigma and tyfonas [45]. Pyrgo are "towers" of low-JCN duplications associated with early-replicating regions and superenhancers, rigma comprise "chasms" of low-JCN deletions enriched in late-replicating fragile sites, and tyfonas are "typhoons" of high-JCN and fold-back inversions. Among these three new patterns, tyfonas share many features expected from the operation of BFB cycles (high JCN in cis, with a high proportion of fold-back inversion junctions), but with additional complexity. Tyfonas were found in $80 \%$ of dedifferentiated liposarcomas and are thought to represent the genomic footprint of supernumerary ring chromosomes in this tumor type [45]. Because FISH studies provided evidence of BFB cycles, nuclear blebbing and micronucleation in well-differentiated liposarcomas [47,48] (carrying genetic aberrations also found in dedifferentiated liposarcomas [67]), it will be important to determine whether or not tyfonas may result from events described in the interphase breakage model.

Funding: The "Genetics of Tumor Suppression" laboratory is supported by grants from the Fondation ARC, the Ligue Nationale Contre le Cancer (Comité Ile-de-France) and the Gefluc.

Acknowledgments: I thank M. Debatisse and I. Simeonova for comments on an early draft of this manuscript.

Conflicts of Interest: The author declares no conflict of interest. The funders had no role in the writing of the manuscript.

\section{References}

1. Umbreit, N.T.; Zhang, C.-Z.; Lynch, L.D.; Blaine, L.J.; Cheng, A.M.; Tourdot, R.; Sun, L.; Almubarak, H.F.; Judge, K.; Mitchell, T.J.; et al. Mechanisms generating cancer genome complexity from a single cell division error. Science 2020, 368, eaba0712. [CrossRef] [PubMed]

2. McClintock, B. Chromosome organization and genic expression. Cold Spring Harb. Symp. Quant. Biol. 1951, 16, 13-47. [CrossRef] [PubMed]

3. Stephens, P.J.; Greenman, C.D.; Fu, B.; Yang, F.; Bignell, G.R.; Mudie, L.J.; Pleasance, E.D.; Lau, K.W.; Beare, D.; Stebbings, L.A.; et al. Massive genomic rearrangement acquired in a single catastrophic event during cancer development. Cell 2011, 144, 27-40. [CrossRef] [PubMed]

4. Toledo, F.; Le Roscouet, D.; Buttin, G.; Debatisse, M. Co-amplified markers alternate in megabase long chromosomal inverted repeats and cluster independently in interphase nuclei at early steps of mammalian gene amplification. EMBO J 1992, 11, 2665-2673. [CrossRef] 
5. Schwab, M.; Amler, L.C. Amplification of cellular oncogenes: A predictor of clinical outcome in human cancer. Genes Chrom. Cancer 1990, 1, 181-193. [CrossRef]

6. Toledo, F.; Smith, K.A.; Buttin, G.; Debatisse, M. The evolution of the amplified adenylate deaminase 2 domains in Chinese hamster cells suggests the sequential operation of different mechanisms of DNA amplification. Mutat. Res. 1992, 276, 261-273. [CrossRef]

7. Coquelle, A.; Toledo, F.; Stern, S.; Bieth, A.; Debatisse, M. A new role for hypoxia in tumor progression: Induction of fragile site triggering genomic rearrangements and formation of complex DMs and HSRs. Mol. Cell 1998, 2, 259-265. [CrossRef]

8. Trask, B.J.; Hamlin, J.L. Early dihydrofolate reductase gene amplification events in CHO cells usually occur on the same chromosome arm as the original locus. Genes Dev. 1989, 3, 1913-1925. [CrossRef]

9. Windle, B.; Draper, B.W.; Yin, Y.X.; O'Gorman, S.; Wahl, G.M. A central role for chromosome breakage in gene amplification, deletion formation, and amplicon integration. Genes Dev. 1991, 5, 160-174. [CrossRef]

10. Ma, C.; Martin, S.; Trask, B.; Hamlin, J.L. Sister chromatid fusion initiates amplification of the dihydrofolate reductase gene in Chinese hamster cells. Genes Dev. 1993, 7, 605-620. [CrossRef]

11. Coquelle, A.; Pipiras, E.; Toledo, F.; Buttin, G.; Debatisse, M. Expression of fragile sites triggers intrachromosomal mammalian gene amplification and sets boundaries to early amplicons. Cell 1997, 89, 215-225. [CrossRef]

12. Smith, K.A.; Gorman, P.A.; Stark, M.B.; Groves, R.P.; Stark, G.R. Distinctive chromosomal structures are formed very early in the amplification of CAD genes in Syrian hamster cells. Cell 1990, 63, 1219-1227. [CrossRef]

13. Smith, K.A.; Stark, M.B.; Gorman, P.A.; Stark, G.R. Fusions near telomeres occur very early in the amplification of CAD genes in Syrian hamster cells. Proc. Natl. Acad. Sci. USA 1992, 89, 5427-5431. [CrossRef] [PubMed]

14. Bertoni, L.; Attolini, C.; Tessera, L.; Mucciolo, E.; Giulotto, E. Telomeric and nontelomeric (TTAGGG)n sequences in gene amplification and chromosome stability. Genomics 1994, 24, 53-62. [CrossRef]

15. Toledo, F.; Buttin, G.; Debatisse, M. The origin of chromosome rearrangements at early stages of AMPD2 gene amplification in Chinese hamster cells. Curr. Biol. 1993, 3, 255-264. [CrossRef]

16. McClintock, B. The fusion of broken ends of sister half-chromatids following chromatid breakage at meiotic anaphases. MO Agric. Exp. Sta. Res. Bull. 1938, 290,1-48.

17. McClintock, B. Mutable loci in maize. Carnegie Inst. Wash. Year Book 1948, 47, 155-169.

18. Sabatier, L.; Ricoul, M.; Pottier, G.; Murnane, J.P. The loss of a single telomere can result in instability of multiple chromosomes in a human tumor cell line. Mol. Cancer Res. 2005, 3, 139-150. [CrossRef]

19. Lo, A.W.I.; Sabatier, L.; Fouladi, B.; Pottier, G.; Ricoul, M.; Murnane, J.P. DNA amplification by breakage/fusion/bridge cycles initiated by spontaneous telomere loss in a human cancer cell line. Neoplasia 2002, 4, 531-538. [CrossRef]

20. McClintock, B. The origin and behavior of mutable loci in maize. Proc. Natl. Acad. Sci. USA 1950, 36, 344-355. [CrossRef]

21. Toledo, F. Mécanismes Précoces D’amplification Génique dans les Cellules de Mammifères [Early Mechanims of Gene Amplification in Mammalian Cells]. Ph.D. Thesis, Université Pierre et Marie Curie, Paris, France, 1994.

22. Hartwell, L.H.; Weinert, T.A. Checkpoints: Controls that ensure the order of cell cycle events. Science 1989, 246, 629-634. [CrossRef] [PubMed]

23. Kuerbitz, S.J.; Plunkett, B.S.; Walsh, W.V.; Kastan, M.B. Wild-type p53 is a cell cycle checkpoint determinant following irradiation. Proc. Natl. Acad. Sci. USA 1992, 89, 7491-7495. [CrossRef] [PubMed]

24. Yin, Y.; Tainsky, M.A.; Bischoff, F.Z.; Strong, L.C.; Wahl, G.M. Wild-type p53 restores cell cycle control and inhibits gene amplification in cells with mutant p53 alleles. Cell 1992, 70, 937-948. [CrossRef]

25. Livingstone, L.R.; White, A.; Sprouse, J.; Livanos, E.; Jacks, T.; Tlsty, T.D. Altered cell cycle arrest and gene amplification potential accompany loss of wild-type p53. Cell 1992, 70, 923-935. [CrossRef]

26. Hartwell, L. Defects in a cell cycle checkpoint may be responsible for the genomic instability of cancer cells. Cell 1992, 71, 543-546. [CrossRef]

27. Gisselsson, D.; Höglund, M.; Mertens, F.; Mitelman, F.; Mandahl, N. Chromosomal organization of amplified chromosome 12 sequences in mesenchymal tumors detected by fluorescence in situ hybridization. Genes Chrom. Cancer 1998, 23, 203-212. [CrossRef] 
28. Shuster, M.I.; Han, L.; Le Beau, M.M.; Davis, E.; Sawicki, M.; Lese, C.M.; Park, N.H.; Colicelli, J.; Gollin, S.M. A consistent pattern of RIN1 rearrangements in oral squamous cell carcinoma cell lines supports a breakage-fusion-bridge cycle model for 11q13 amplification. Genes Chrom. Cancer 2000, 28, 153-163. [CrossRef]

29. Hellman, A.; Zlotorynski, E.; Scherer, S.W.; Cheung, J.; Vincent, J.B.; Smith, D.I.; Trakhtenbrot, L.; Kerem, B. A role for common fragile site induction in amplification of human oncogenes. Cancer Cell 2002, 1, 89-97. [CrossRef]

30. Ciullo, M.; Debily, M.-A.; Rozier, L.; Autiero, M.; Billault, A.; Mayau, V.; El Marhomy, S.; Guardiola, J.; Bernheim, A.; Coullin, P.; et al. Initiation of the breakage-fusion-bridge mechanism through common fragile site activation in human breast cancer cells: The model of PIP gene duplication from a break at FRA7I. Hum. Mol. Genet. 2002, 11, 2887-2894. [CrossRef]

31. Reshmi, S.C.; Huang, X.; Schoppy, D.W.; Black, R.C.; Saunders, W.S.; Smith, D.I.; Gollin, S.M. Relationship between FRA11F and 11q13 gene amplification in oral cancer. Genes Chrom. Cancer 2007, 46, 143-154. [CrossRef]

32. Marotta, M.; Onodera, T.; Johnson, J.; Budd, G.T.; Watanabe, T.; Cui, X.; Giuliano, A.E.; Niida, A.; Tanaka, H. Palindromic amplification of the ERBB2 oncogene in primary HER2-positive breast tumors. Sci. Rep. 2017, 7, 41921. [CrossRef] [PubMed]

33. Gisselsson, D.; Höglund, M.; Mertens, F.; Johansson, B.; Dal Cin, P.; Van den Berghe, H.; Earnshaw, W.C.; Mitelman, F.; Mandahl, N. The structure and dynamics of ring chromosomes in human neoplastic and non-neoplastic cells. Hum. Genet. 1999, 104, 315-325. [CrossRef] [PubMed]

34. Reshmi, S.C.; Roychoudhury, S.; Yu, Z.; Feingold, E.; Potter, D.; Saunders, W.S.; Gollin, S.M. Inverted duplication pattern in anaphase bridges confirms the breakage-fusion-bridge (BFB) cycle model for 11q13 amplification. Cytogenet. Genome Res. 2007, 116, 46-52. [CrossRef] [PubMed]

35. Zhu, C.; Mills, K.D.; Ferguson, D.O.; Lee, C.; Manis, J.; Fleming, J.; Gao, Y.; Morton, C.C.; Alt, F.W. Unrepaired DNA breaks in p53-deficient cells lead to oncogenic gene amplification subsequent to translocations. Cell 2002, 109, 811-821. [CrossRef]

36. Artandi, S.E.; Chang, S.; Lee, S.L.; Alson, S.; Gottlieb, G.J.; Chin, L.; DePinho, R.A. Telomere dysfunction promotes non-reciprocal translocations and epithelial cancers in mice. Nature 2000, 406, 641-645. [CrossRef]

37. Difilippantonio, M.J.; Petersen, S.; Chen, H.T.; Johnson, R.; Jasin, M.; Kanaar, R.; Ried, T.; Nussenzweig, A. Evidence for replicative repair of DNA double-strand breaks leading to oncogenic translocation and gene amplification. J. Exp. Med. 2002, 196, 469-480. [CrossRef]

38. Lim, G.; Karaskova, J.; Beheshti, B.; Vukovic, B.; Bayani, J.; Selvarajah, S.; Watson, S.K.; Lam, W.L.; Zielenska, M.; Squire, J.A. An integrated mBAND and submegabase resolution tiling set (SMRT) CGH array analysis of focal amplification, microdeletions, and ladder structures consistent with breakage-fusion-bridge cycle events in osteosarcoma. Genes Chrom. Cancer 2005, 42, 392-403. [CrossRef]

39. Miller, C.T.; Lin, L.; Casper, A.M.; Lim, J.; Thomas, D.G.; Orringer, M.B.; Chang, A.C.; Chambers, A.F.; Giordano, T.J.; Glover, T.W.; et al. Genomic amplification of MET with boundaries within fragile site FRA7G and upregulation of MET pathways in esophageal adenocarcinoma. Oncogene 2006, 25, 409-418. [CrossRef]

40. Pelliccia, F.; Bosco, N.; Rocchi, A. Breakages at common fragile sites set boundaries of amplified regions in two leukemia cell lines K562-Molecular characterization of FRA2H and localization of a new CFS FRA2S. Cancer Lett. 2010, 299, 37-44. [CrossRef]

41. Blumrich, A.; Zapatka, M.; Brueckner, L.M.; Zheglo, D.; Schwab, M.; Savelyeva, L. The FRA2C common fragile site maps to the borders of MYCN amplicons in neuroblastoma and is associated with gross chromosomal rearrangements in different cancers. Hum. Mol. Genet. 2011, 20, 1488-1501. [CrossRef]

42. Kinsella, M.; Bafna, V. Combinatorics of the breakage-fusion-bridge mechanism. J. Comput. Biol. 2012, 19, 662-678. [CrossRef] [PubMed]

43. Zakov, S.; Kinsella, M.; Bafna, V. An algorithmic approach for breakage-fusion-bridge detection in tumor genomes. Proc. Natl. Acad. Sci. USA 2013, 110, 5546-5551. [CrossRef] [PubMed]

44. Zakov, S.; Bafna, V. Reconstructing breakage fusion bridge architectures using noisy copy numbers. J. Comput. Biol. 2015, 22, 577-594. [CrossRef] [PubMed]

45. Hadi, K.; Yao, X.; Behr, J.M.; Deshpande, A.; Xanthopoulakis, C.; Tian, H.; Kudman, S.; Rosiene, J.; Darmofal, M.; DeRose, J.; et al. Distinct Classes of Complex Structural Variation Uncovered across Thousands of Cancer Genome Graphs. Cell 2020, 183, 197-210.e32. [CrossRef] [PubMed] 
46. Marotta, M.; Chen, X.; Inoshita, A.; Stephens, R.; Budd, G.T.; Crowe, J.P.; Lyons, J.; Kondratova, A.; Tubbs, R.; Tanaka, H. A common copy-number breakpoint of ERBB2 amplification in breast cancer colocalizes with a complex block of segmental duplications. Breast Cancer Res. 2012, 14, R150. [CrossRef] [PubMed]

47. Pedeutour, F.; Suijkerbuijk, R.F.; Forus, A.; Van Gaal, J.; Van de Klundert, W.; Coindre, J.M.; Nicolo, G.; Collin, F.; Van Haelst, U.; Huffermann, K. Complex composition and co-amplification of SAS and MDM2 in ring and giant rod marker chromosomes in well-differentiated liposarcoma. Genes Chrom. Cancer 1994, 10, 85-94. [CrossRef]

48. Iwasaki, H.; Ohjimi, Y.; Ishiguro, M.; Isayama, T.; Fujita, C.; Kaneko, Y.; Kikuchi, M.; Shinohara, N. Supernumerary ring chromosomes and nuclear blebs in some low-grade malignant soft tissue tumours: Atypical lipomatous tumours and dermatofibrosarcoma protuberans. Virchows Archiv. 1998, 432, 521-528. [CrossRef]

49. Gisselsson, D.; Björk, J.; Höglund, M.; Mertens, F.; Dal Cin, P.; Akerman, M.; Mandahl, N. Abnormal nuclear shape in solid tumors reflects mitotic instability. Am. J. Pathol. 2001, 158, 199-206. [CrossRef]

50. Ambros, I.M.; Rumpler, S.; Luegmayr, A.; Hattinger, C.M.; Strehl, S.; Kovar, H.; Gadner, H.; Ambros, P.F. Neuroblastoma cells can actively eliminate supernumerary MYCN gene copies by micronucleus formation-Sign of tumour cell revertance? Eur. J. Cancer 1997, 33, 2043-2049. [CrossRef]

51. Crasta, K.; Ganem, N.J.; Dagher, R.; Lantermann, A.B.; Ivanova, E.V.; Pan, Y.; Nezi, L.; Protopopov, A.; Chowdhury, D.; Pellman, D. DNA breaks and chromosome pulverization from errors in mitosis. Nature 2012, 482, 53-58. [CrossRef]

52. Zhang, C.-Z.; Spektor, A.; Cornils, H.; Francis, J.M.; Jackson, E.K.; Liu, S.; Meyerson, M.; Pellman, D. Chromothripsis from DNA damage in micronuclei. Nature 2015, 522, 179-184. [CrossRef] [PubMed]

53. Nones, K.; Waddell, N.; Wayte, N.; Patch, A.-M.; Bailey, P.; Newell, F.; Holmes, O.; Fink, J.L.; Quinn, M.C.J.; Tang, Y.H.; et al. Genomic catastrophes frequently arise in esophageal adenocarcinoma and drive tumorigenesis. Nat. Commun. 2014, 5, 5224. [CrossRef] [PubMed]

54. Li, Y.; Schwab, C.; Ryan, S.; Papaemmanuil, E.; Robinson, H.M.; Jacobs, P.; Moorman, A.V.; Dyer, S.; Borrow, J.; Griffiths, M.; et al. Constitutional and somatic rearrangement of chromosome 21 in acute lymphoblastic leukaemia. Nature 2014, 508, 98-102. [CrossRef] [PubMed]

55. Cortés-Ciriano, I.; Lee, J.J.-K.; Xi, R.; Jain, D.; Jung, Y.L.; Yang, L.; Gordenin, D.; Klimczak, L.J.; Zhang, C.-Z.; Pellman, D.S.; et al. Comprehensive analysis of chromothripsis in 2,658 human cancers using whole-genome sequencing. Nat. Genet. 2020. [CrossRef]

56. Maciejowski, J.; Li, Y.; Bosco, N.; Campbell, P.J.; de Lange, T. Chromothripsis and Kataegis Induced by Telomere Crisis. Cell 2015, 163, 1641-1654. [CrossRef]

57. Shimizu, N.; Shingaki, K.; Kaneko-Sasaguri, Y.; Hashizume, T.; Kanda, T. When, where and how the bridge breaks: Anaphase bridge breakage plays a crucial role in gene amplification and HSR generation. Exp. Cell Res. 2005, 302, 233-243. [CrossRef]

58. Maciejowski, J.; Chatzipli, A.; Dananberg, A.; Chu, K.; Toufektchan, E.; Klimczak, L.J.; Gordenin, D.A.; Campbell, P.J.; de Lange, T. APOBEC3-dependent kataegis and TREX1-driven chromothripsis during telomere crisis. Nat. Genet. 2020, 52, 884-890. [CrossRef]

59. Dixon, J.R.; Selvaraj, S.; Yue, F.; Kim, A.; Li, Y.; Shen, Y.; Hu, M.; Liu, J.S.; Ren, B. Topological domains in mammalian genomes identified by analysis of chromatin interactions. Nature 2012, 485, 376-380. [CrossRef]

60. Rao, S.S.P.; Huntley, M.H.; Durand, N.C.; Stamenova, E.K.; Bochkov, I.D.; Robinson, J.T.; Sanborn, A.L.; Machol, I.; Omer, A.D.; Lander, E.S.; et al. A 3D map of the human genome at kilobase resolution reveals principles of chromatin looping. Cell 2014, 159, 1665-1680. [CrossRef]

61. Akdemir, K.C.; Le, V.T.; Chandran, S.; Li, Y.; Verhaak, R.G.; Beroukhim, R.; Campbell, P.J.; Chin, L.; Dixon, J.R.; Futreal, P.A.; et al. Disruption of chromatin folding domains by somatic genomic rearrangements in human cancer. Nat. Genet. 2020, 52, 294-305. [CrossRef]

62. Korbel, J.O.; Campbell, P.J. Criteria for inference of chromothripsis in cancer genomes. Cell 2013, 152, 1226-1236. [CrossRef] [PubMed]

63. Baca, S.C.; Prandi, D.; Lawrence, M.S.; Mosquera, J.M.; Romanel, A.; Drier, Y.; Park, K.; Kitabayashi, N.; MacDonald, T.Y.; Ghandi, M.; et al. Punctuated evolution of prostate cancer genomes. Cell 2013, 153, 666-677. [CrossRef] [PubMed] 
64. Spies, N.; Weng, Z.; Bishara, A.; McDaniel, J.; Catoe, D.; Zook, J.M.; Salit, M.; West, R.B.; Batzoglou, S.; Sidow, A. Genome-wide reconstruction of complex structural variants using read clouds. Nat. Methods 2017, 14, 915-920. [CrossRef] [PubMed]

65. Li, Y.; Roberts, N.D.; Wala, J.A.; Shapira, O.; Schumacher, S.E.; Kumar, K.; Khurana, E.; Waszak, S.; Korbel, J.O.; Haber, J.E.; et al. Patterns of somatic structural variation in human cancer genomes. Nature 2020, 578, 112-121. [CrossRef] [PubMed]

66. ICGC/TCGA Pan-Cancer Analysis of Whole Genomes Consortium Pan-cancer analysis of whole genomes. Nature 2020, 578, 82-93. [CrossRef] [PubMed]

67. Thway, K. Well-differentiated liposarcoma and dedifferentiated liposarcoma: An updated review. Semin. Diagn. Pathol. 2019, 112-121. [CrossRef] [PubMed]

Publisher's Note: MDPI stays neutral with regard to jurisdictional claims in published maps and institutional affiliations.

(C) 2020 by the author. Licensee MDPI, Basel, Switzerland. This article is an open access article distributed under the terms and conditions of the Creative Commons Attribution (CC BY) license (http://creativecommons.org/licenses/by/4.0/). 